\title{
Electrochemical Determination of Ciprofloxacin Based on the Enhancement Effect of Sodium Dodecyl Benzene Sulfonate
}

\author{
Shenghui Zhang and Shuang Wei \\ Kev Laboratory of Biological Resources Protection and Ltilization of Hubei Province, Hubei Institute for Nationalities, \\ Enshi $4+5000$, P.R. China. . E-mail: zhang_shenghtial $163 . c 0 m$ \\ Received October 23, 2006
}

\begin{abstract}
Herein a new electrochemical method was described for the determination of ciprofloxacin based on the enhancement effect of an anionic surfactant: sodium dodecyl benzene sulfonate (SDBS). In pH 4.0 phosphate buffer and in the presence of $1.0 \times 10^{-4} \mathrm{~mol} / \mathrm{L}$ SDBS. ciprofloxacin yields a well-defined and sensitive oxidation peak at the carbon paste electrode (CPE). Compared with that in the absence of SDBS. the oxidation peak current of ciprofloxacin remarkably increases in the presence of SDBS. The experimental parameters. such as supporting electrolyte concentration of SDBS, and accumulation time. were optimized for ciprofloxacin detenmination. The oxidation peak current is proportional to the concentration of ciprofloxacin over the range from $8.0 \times 10^{-8}$ to $5.0 \times 10^{-6} \mathrm{~mol} \mathrm{~L}^{-1}$. The detection limit is $2.0 \times 10^{-8} \mathrm{~mol} \mathrm{~L}^{-1}$ after 2 min of accumulation. This new voltammetric method was successfully used to detect ciprofloxacin in dnugs.
\end{abstract}

Key Words : Ciprofloxacin. Voltammetric determination. Surfactant, Carbon paste electrode

\section{Introduction}

Drug analysis is an important branch of analytical chemistry: It plays important role in drug quality control and has wide impacts on public health. Therefore developing sensitive. simple rapide and reliable method for the determination of active ingredient is valuable and necessary.

Ciprofloxacin (1-cyclopropy 1-6-fluoro-1 4-dilydro-4-oxo7-(1-piperazinyl)-3-quinoline carboxylic acid. Fig. 1) is a synthetic broad spectnum antibiotic used for treating infections caused by different bacteria. Ciprofloxacin is also one of the antibiotics approved by the FDA for patients who have been exposed to the inhaled form of anthrax. Its mode of action depends upon blocking bacterial DNA replication by binding itself to an enzyme called DNA gyrase. thereby' preventing the enzy'me's ability to untwist the DNA double helix. which is required for DNA replication.

According to literatures. the widely-used method for the determination of ciprofloxacin is high performance liquid chromatography (HPLC) $)^{1-5}$ since it possesses high sensitivity' and excellent selectivity. Additionally. many other methods such as spectrophotometry. ${ }^{67}$ capillary zone electrophoresis. ${ }^{8}$ micellar liquid chromatography. ${ }^{9}$ chemiluminescence $e^{9.10}$ and biosensor ${ }^{12}$ were also reported for the analysis of ciprofloxacin. However. electrochemical method for the deter-<smiles>O=C(O)c1cn(C2CC2)c2cc(N3CCNCC3)c(F)cc2c1=O</smiles>

Figure 1. Chemical structure of ciproflosacin. mination of ciprofloxacin is rarely reported although electrochemical method has many advantages: ligh sensitivity. good sensitivity rapid response. low cost and simplicity:

The main objective of the current work is to develop an electrochemical method for the detenmination of ciprofloxacin utilizing the enhancement effect of surfactant. Surfactant has a long hydrophobic $\mathrm{C}-\mathrm{H}$ chain and a hydrophilic head group. Therefore. it can adsorb at hydrophobic electrode surface and then alter the properties of electrode/solution interface Finally: surfactant heavily influences the electrochemical process of electroactive species. ${ }^{13-17}$ To date surfactant was widely' used in electroanalytical chemistry to improve the sensitivity and selectivity. In $\mathrm{pH} 4.0$ phosphate buffer. ciprofloxacin yields an oxidation peak at the carbon paste electrode (CPE) after accumulation. However. the peak current is relatively low. In order to greatly improve the sensitivity: low concentration of surfactant was employed. It is found that the oxidation peak current of ciprofloxacin significantly enhances after adding low concentration of sodium dodecyl benzene sulfonate (SDBS). suggesting that SDBS facilitate the electron transfer of ciprofloxacin. Without a doubt. the sensitivity of determining ciprofloxacin must be greatly improved in the presence of SDBS. Based on this. a novel. sensitive and simple voltanmetric method was proposed for the determination of ciprofloxacin.

\section{Experimental}

Reagents. All chemicals were of analytical-reagent grade and used without further purification. $1.00 \times 10^{-2} \mathrm{~mol} \mathrm{~L}^{-1}$ ciprofloxacin stock solution was prepared by dissolving ciprofloxacin (Sigma) into $0.01 \mathrm{~mol} \mathrm{~L}^{-1} \mathrm{HCl}$. Working solutions were prepared daily by suitable dilution with 0.01 mol L $\mathrm{L}^{-1} \mathrm{HCl}$.

Sodium dodecyl benzene sulfonate (SDBS) (Shanghai 
Reagent Corporation. China) was made into $1.0 \times 10^{-2}$ mol $\mathrm{L}^{-1}$ aqueous solutions. Spectroscopic graphite powder and paraffin oil were purchased from Shanghai Reagent Corporation. China.

Apparatus. All the electrochemical measurements were performed with a $\mathrm{CHI} 660 \mathrm{~A}$ Electrochemical Workstation (CH Instrument. USA). A three-electrode system. including CPE working electrode ( $3 \mathrm{~mm}$ in diameter). a platinum wire counter electrode and a saturated calomel reference electrode (SCE), was employed.

Preparation of the CPE. The carbon paste electrode was prepared by mixing $50.0 \mathrm{mg}$ graphite powder and $20.0 \mu \mathrm{L}$ paraffin oil in a small mortar. then this mixture was homogenized. After that the paste was pressed into the cavity of the electrode body and the surface was smoothed against weighing paper. Unless otherwise stated the paste was carefully removed and another new CPE was remade after each measurement.

Determination of ciprofloxacin. The carbon paste electrode was firstly activated in $\mathrm{pH} 4.0$ phosphate buffer using successive cyclic sweep from $0.30 \mathrm{~V}$ to $1.30 \mathrm{~V}$ until the cyclic voltammograms were stable. After that a known concentration of ciprofloxacin and $1.0 \times 10^{-4} \mathrm{~mol} \mathrm{~L}^{-1}$ SDBS were added into and the differential pulse voltammogramms were recorded after 2 min open-circuit accumulation. The oxidation peak current was measured at $1.06 \mathrm{~V}$.

\section{Results and Discussion}

Electrochemical responses of ciprofloxacin. Figure 2 shows the successive cyclic voltammograms of $1.0 \times 10^{-5}$ mol $\mathrm{L}^{-1}$ ciprofloxacin at CPE. In $0.1 \mathrm{~mol} \mathrm{\textrm {L } ^ { - 1 }}, \mathrm{pH} 4.0$ phosphate buffer and in the presence of $1.0 \times 10^{-4} \mathrm{~mol} \mathrm{~L}^{-1}$ SDBS, an obvious oxidation peak appears at $1.10 \mathrm{~V}$ during the first anodic sweep from 0.30 to $1.30 \mathrm{~V}$. On the reverse scan. no corresponding reduction peak is observed. revealing that the electrode process of ciprofloxacin is totally irreversible

Figure 2 also tells that the oxidation peak current grad-

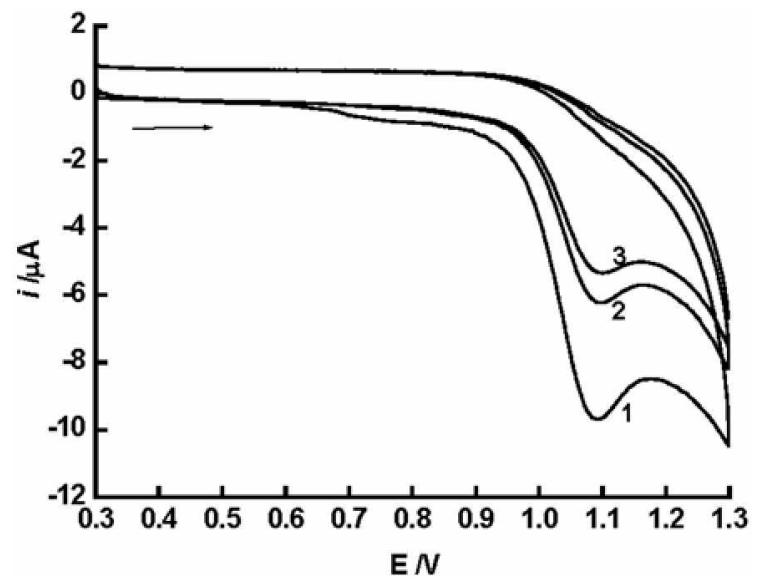

Figure 2. Successive cyclic voltammograms of $1.0 \times 10^{-5} \mathrm{~mol} \mathrm{~L}^{-1}$ ciproflosacin at CPE and in the presence of $1.0 \times 10^{-1} \mathrm{mmol} / \mathrm{L}$ SDBS. Scan rate: $100 \mathrm{mV} \mathrm{s}^{-1}$.

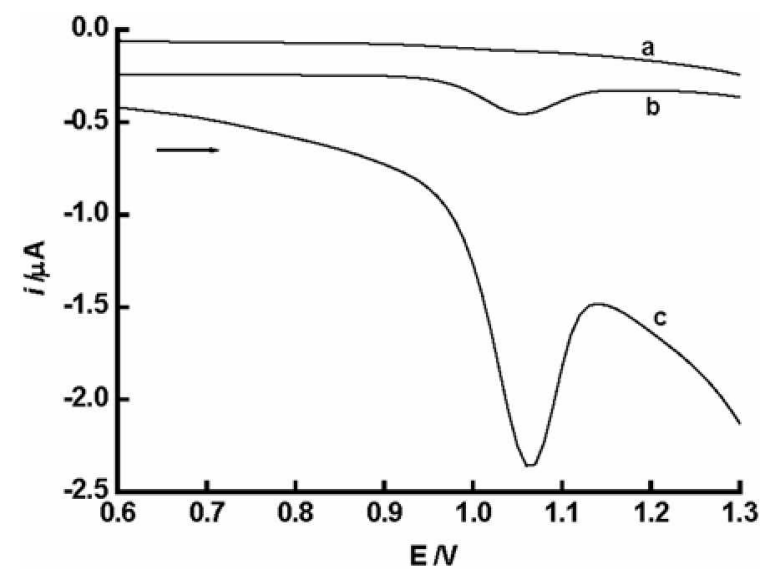

Figure 3. DP voltammograms of ciprofloxacm at CPE in $0.1 \mathrm{~mol}$ $\mathrm{L}^{-1}$ phosphate buffer ( $\mathrm{pH} 4.0$ ). (a): blank voltammograms, (b): 5.0 $\times 10^{-7} \mathrm{~mol} \mathrm{~L}{ }^{-1}$ ciprofloxacin, (c): (b) $+1.0 \times 10^{-4} \mathrm{~mol} \mathrm{~L}-1$ SDBS. The DPV parameters: pulse amplitude $=50 \mathrm{mV}$, scan rate $=20 \mathrm{mV}$ $\mathrm{s}^{-1}$, pulse width $=50 \mathrm{~ms}$, accumulation time: $2 \mathrm{~min}$.

ually decreases as increasing the number of cyclic potential sweeps. The decreases in peak current may be caused by the fact that the adsorption of ciprofloxacin or its oxidative product occurs at CPE surface. The adsorption fouls the electrode surface and retards the electro-oxidation of ciprofloxacin. Therefore the oxidation peak current in the first anodic sweep was recorded for ciprofloxacin analysis in the following studies to acquire higher sensitivity and better reproducibility.

In order to show the enhancement effect of SDBS. the electrochemical oxidation of ciprofloxacin at CPE in the absence and presence of SDBS were compared by differential pulse voltammetry (DPV). Figure 3 shows the comparisons with DPV parameters: pulse amplitude $=50 \mathrm{mV}$. scan rate $=20 \mathrm{mV} \mathrm{s}^{-1}$. pulse width $=50 \mathrm{~ms}$, accumulation time $=2 \mathrm{~min}$. In $0.1 \mathrm{~mol} \mathrm{~L}{ }^{-1}$. $\mathrm{pH} 4.0$ phosphate buffer. $5.0 \times$ $10^{-7}$ mol L $\mathrm{L}^{-1}$ ciprofloxacin yields a very weak oxidation peak at $1.06 \mathrm{~V}$ at the CPE (Fig. 3b). However the oxidation peak current greatly increases after adding $1.0 \times 10^{-4} \mathrm{~mol} \mathrm{~L}^{-1}$ SDBS (Fig. 3c). The remarkable peak current enhancement reveals that SDBS facilitates the electron transfer of ciprofloxacin. Otherwise, the DP voltammograms of C.PE in 0.1 mol L ${ }^{-1}$ phosphate buffer $(\mathrm{pH} 4.0)$ containing $1.0 \times 10^{-4} \mathrm{~mol}$ $\mathrm{L}^{-1}$ SDBS are given in Figure $3 \mathrm{a}$ for comparison. Compared with curves (a) and (c), it is very clear that the oxidation peak at $1.06 \mathrm{~V}$ corresponds to ciprofloxacin. From Figure 3. conclusion can be made that SDBS significantly improves the determining sensitivity of ciprofloxacin.

Choice of supporting electrolyte. In electrochemical determination. choice of suitable supporting electrolyte (sometimes called determining medium) is very important since the electrochenical responses of ciprofloxacin show great difference in different supporting electrolytes. In this work. the electrochenical oxidation responses of ciprofloxacin in a variety of determining mediums. such as $\mathrm{HClO}_{4}$. $\mathrm{KCl}, \mathrm{NaOH}$. pH 3.5-5.5 HAc-NaAc buffer. $\mathrm{pH} 4.0-8.0$ phosphate buffer (each $0.1 \mathrm{~mol} \mathrm{~L}^{-1}$ ) containing different concentration of SDBS from 0 to $2.0 \times 10^{-4} \mathrm{~mol} \mathrm{~L}^{-1}$ were 


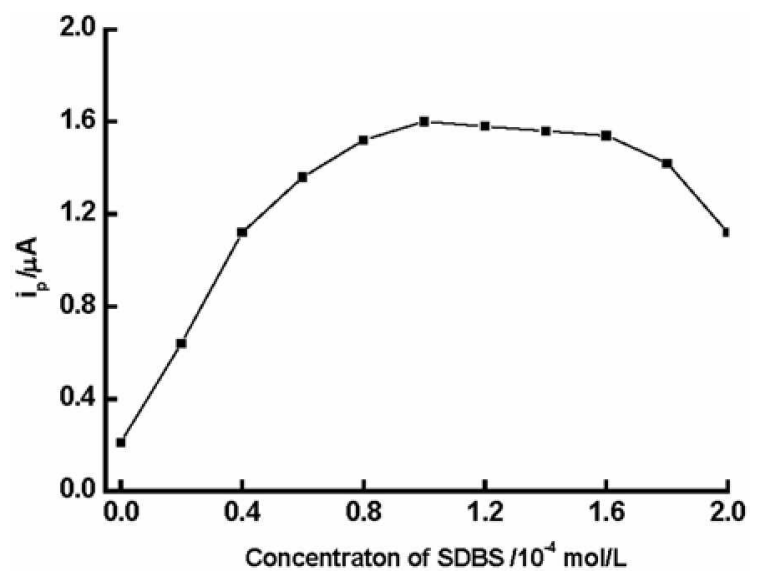

Figure 4. Effect of the concentration of SDBS on the oxidation peak current of $5.0 \times 10^{-5} \mathrm{~mol} \mathrm{~L}-1$ ciprofloxacin.

investigated in details. It is found that the oxidation peak current is highest in $0.1 \mathrm{~mol} \mathrm{~L}^{-1}$. $\mathrm{pH} 4.0$ phosphate buffer containing $1.0 \times 10^{-4} \mathrm{~mol} \mathrm{~L}^{-1}$ SDBS. Otherwise, the background current is very low and the oxidation peak is wellshaped. Therefore. $0.1 \mathrm{~mol} \mathrm{~L}^{-1}$ phosphate buffer $(\mathrm{pH}+0)$ containing $1.0 \times 10^{-4} \mathrm{~mol} \mathrm{~L}^{-1}$ SDBS was used as supporting electrolyte for the determination of ciprofloxacin.

Effect of SDBS concentration. Although SDBS can improve the oxidation peak current of ciprofloxacin. the peak current enhancement is closely related to the concentration of SDBS. The relationship between the oxidation peak current of ciprofloxacin and the concentration of SDBS is illustrated in Figure 4. As gradual improving the concentration of SDBS from 0 to $0.8 \times 10^{-4} \mathrm{~mol} \mathrm{~L}^{-1}$. the oxidation peak current firstly increases gradually: when further improving the SDBS concentration to $1.6 \times 10^{-4} \mathrm{~mol} \mathrm{~L}^{-1}$. the oxidation peak current changes slightly. However. when the concentration of SDBS is higher than $1.6 \times 10^{-4} \mathrm{~mol} \mathrm{~L}^{-1}$. the oxidation peak current of ciprofloxacin conversely decreases. Therefore the concentration of SDBS is chosen as $1.0 \times 10^{-4} \mathrm{~mol} \mathrm{~L}^{-1}$ in this work.

Influence of scan rate. The oxidation peak currents of $5.0 \times 10^{-6} \mathrm{~mol} \mathrm{~L}^{-1}$ ciprofloxacin in the presence of $1.0 \times 10^{-4}$ $\mathrm{mol} \mathrm{L}{ }^{-1}$ SDBS and at different scan rates from 25 to $300 \mathrm{mV}$ $\mathrm{s}^{-1}$ were measured by linear sweep voltanmetry (LSV). It is found that the oxidation peak current is proportional to the scan rate. suggesting that the oxidation of ciprofloxacin at CPE is adsorption-controlled. ${ }^{18}$

Effect of accumulation time. Accumulation is a simple and effective way to enhance the determining sensitivity. In this work. open-circuit accumulation was employed to further improve the oxidation peak current of ciprofloxacin in the presence of SDBS. Figure 5 shows the dependence of oxidation peak current on accumulation time. When the accumulation time increases from 0 to $2 \mathrm{~min}$, the oxidation peak current increases linearly: However. with further increasing accumulation time the plots become curved. The curvature presumably indicates that the limiting value of the amount of ciprofloxacin at CPE has been achieved. Considering both sensitivity and working efficiency. an accumu-

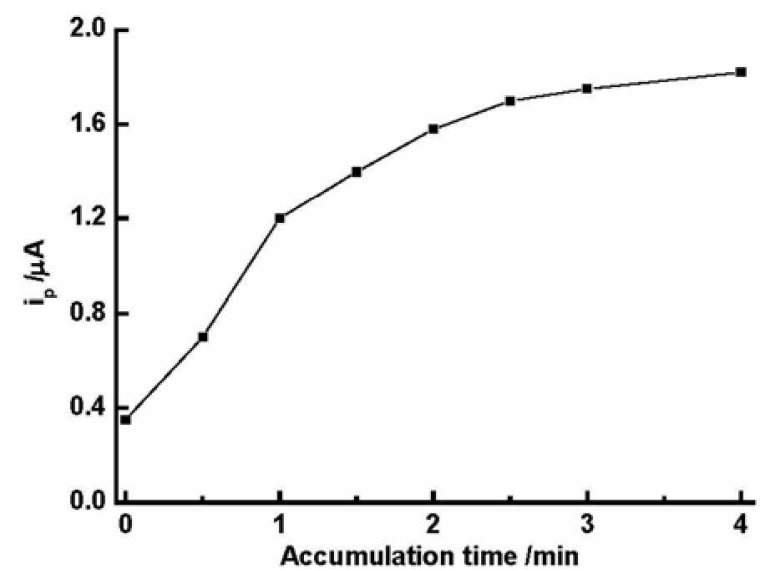

Figure 5. Influence of accumulation time on the oxidation peak current of $5.0 \times 10^{-3} \mathrm{~mol} \mathrm{~L}^{-1}$ ciproflosacin.

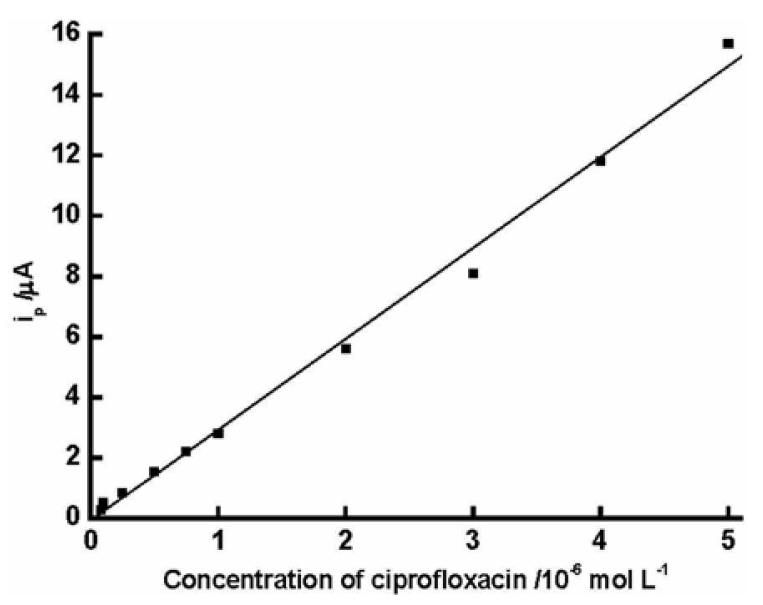

Figure 6. Calibration curve for elprofloxacin.

lation time of $2 \mathrm{~min}$ was employed

Calibration curve for ciprofloxacin. The relationship between the oxidation peak current and the concentration of ciprofloxacin was examined using DPV. and the results shown in Figure 6. It is found that the oxidation peak current $\left(\mathrm{i}_{F}\right)$ is proportional to the concentration of ciprofloxacin over the range from $8.0 \times 10^{-8} \mathrm{~mol} / \mathrm{L}$ to $5.0 \times 10^{-6} \mathrm{~mol} / \mathrm{L}$ and obey's the following equation: $\mathrm{i}_{\mathrm{p}}=0.076+3.08 \times 10^{6} \mathrm{C}(\mathrm{r}=$ 0.996. $\mathrm{C}$ in $\mathrm{mol} / \mathrm{L}$ ). The detection limit was estimated to be $2.0 \times 10^{-8} \mathrm{~mol} / \mathrm{L}$.

After each measurement. the carbon paste was carefully removed from the cavity and another new CPE was remade as above-mentioned procedure. The reproducibility between multiple electrode preparations was estimated by comparing the oxidation peak current of $5.0 \times 10^{-7} \mathrm{~mol} / \mathrm{L}$ ciprofloxacin. The relative standard deviation (RSD) is $5.6 \%$ for $10 \mathrm{CPEs}$, revealing that this method possesses good reproducibility and potential applications

Interference. To estimate the interferences of foreign species (especially other structurally similar substances) on the determination of ciprofloxacin at the level of $5.0 \times 10^{-7}$ mol L-1 a sy stematic study was carried out (see Table 1). It is found that many other foreign substances have no influence on the determination of ciprofloxacin. For example. 500- 
Table 2. Determination of ciprofloxacin in drugs

\begin{tabular}{llccc}
\hline \multicolumn{1}{c}{ Samples } & Declared content & Detected by HPLC & Detected by this method & Recovery (\%) \\
\hline Ciprofloxacin hydrochloride eye drops A & $3.00 \mathrm{mg} \mathrm{mL}^{-1}$ & $2.96 \mathrm{mg} \mathrm{mL}^{-1}$ & $2.92 \mathrm{mg} \mathrm{mL}^{-1}$ & 99.4 \\
Ciprofloxacin hydrochloride eye drops B & $3.00 \mathrm{mg} \mathrm{mL} \mathrm{mL}^{-1}$ & $2.92 \mathrm{mg} \mathrm{mL}$ & $2.88 \mathrm{mg} \mathrm{mL}^{-1}$ & 99.2 \\
Ciprofloxacin hydrochloride tablet A & $0.25 \mathrm{~g} \mathrm{per} \mathrm{tablet}$ & $0.22 \mathrm{~g} \mathrm{per} \mathrm{tablet}$ & $0.20 \mathrm{~g} \mathrm{per} \mathrm{táblet}^{-1}$ & 98.8 \\
Ciprofloxacin hydrochloride tablet B & $0.25 \mathrm{~g}$ per tablet & $0.27 \mathrm{~g}$ per táblet & $0.28 \mathrm{~g} \mathrm{per} \mathrm{tablet}$ & 99.6 \\
\hline
\end{tabular}

Table 1. Interferences of foreign species on the oxidation peak curnent of $5.0 \times 10^{-5} \mathrm{~mol} \mathrm{~L}^{-1}$ ciprofloxacin

\begin{tabular}{lcc}
\hline \multicolumn{1}{c}{ Interferents } & Concentration (mol L $\left.{ }^{-1}\right)$ & Signal change (\%) \\
\hline Ascorbic acid & $2.5 \times 10^{-4}$ & +1.4 \\
(AA) & & \\
Uric acid (UA) & $2.5 \times 10^{-4}$ & +3.2 \\
Dopamine (DA) & $2.5 \times 10^{-4}$ & +1.6 \\
Xanthine (XA) & $2.5 \times 10^{-4}$ & +3.5 \\
Cafteine & $2.5 \times 10^{-4}$ & -2.6 \\
Vitamin E & $2.5 \times 10^{-4}$ & -3.6 \\
Pefloxacin & $5.0 \times 10^{-5}$ & +4.2 \\
Ofloxacin & $5.0 \times 10^{-5}$ & -3.8 \\
Nortloxacin & $5.0 \times 10^{-5}$ & +4.4 \\
Trovafloxacin & $5.0 \times 10^{-5}$ & -4.6 \\
Gatifloxacin & $5.0 \times 10^{-5}$ & -3.6 \\
\hline
\end{tabular}

fold concentration of ascorbic acid (AA). uric acid (UA). dopamine (DA), xanthine (XA). caffeine. vitamin E. 100fold concentration of pefloxacin. ofloxacin. norfloxacin. trovafloxacin. and gatifloxacin. almost do not interfere with the current response of $5.0 \times 10^{-7} \mathrm{~mol} \mathrm{~L}{ }^{-1}$ ciprofloxacin (signal change below $5 \%$ ), suggesting that this newly proposed method has excellent selectivity toward ciprofloxacin.

Drug analysis. This new method was used to detect ciprofloxacin in the ciprofloxacin hydrochloride eye drops and ciprofloxacin hydrochloride tablets. No pretreatment for the ciprofloxacin hydrochloride eye was done except for dilution with $0.1 \mathrm{~mol} \mathrm{~L}^{-1} . \mathrm{pH} 4.0$ phosphate buffer.

The average mass of five tablets was determined and finely powdered then the required amount of sample to prepare a solution of $c a \cdot 10^{-3} \mathrm{~mol} \mathrm{~L}^{-1}$ was transferred into a $100-\mathrm{mL}$ standard flask containing $80 \mathrm{~mL}$ of $0.1 \mathrm{~mol} \mathrm{~L}^{-1}$ phosphate buffer $(\mathrm{pH} 4.0)$. The contents of flask were stirred magnetically for $30 \mathrm{~min}$. then diluted to volume with the same supporting electrolyte and kept for $4 \mathrm{~h}$. After that it was centrifugated for $20 \mathrm{~min}$ at the speed of $3000 \mathrm{rpm}$. When determining ciprofloxacin. a certain volume of the resulting clear solution was added into $10.0 \mathrm{~mL}$ supporting electrolyte and DP voltammograms were recorded as in standard ciprofloxacin.

The content of ciprofloxacin was determined by standard addition method and the results shown in Table 2. The results obtained by this method are in good agreement with the declared ciprofloxacin content and the results obtained by HPLC. Furthermore in order to establish the suitability of the proposed method known amounts of standard ciprofloxacin were added into the analytical solution. and the same procedure was applied. The recoveries indicate that the accuracy and repeatability of this proposed method are very good. From above experimental results. it is very clear that this novel method has great potential for practical sample analysis

\section{Conclusion}

In this work. SDBS adsorbs onto CPE surface via hydrophobic interaction between $\mathrm{C} \cdot \mathrm{H}$ chain and graphite, altering the structure and property of the $\mathrm{CPE} /$ solution interface. Therefore, the electrochemical responses of ciprofloxacin show great difference in the presence of SDBS. Under the obvious enhancement effect of SDBS. both the oxidation peak current and the detemining sensitivity of ciprofloxacin are significantly improved.

Acknowledgements. The authors are grateful to the Natural Science Foundation of Hubei Province (2004ABA235) and the Natural Science Foundation of Hubei Provincial Department of Education (D200529004) for financial supports.

\section{References}

1. Neckel. U; Joukhadar. C.; Frossard. M; Jager, W; Muller. M.; Mayer. B. X. Anal Chint Acta 2003. 463.199.

2. Idown. O. R.: Peggins. I. O. J. Phomtacent. Bioned dinal. 2004. 35. 143.

3. Wbiralova. Z.: Nobilis. M.: Zoulova. J.: Kvetina. T.: Petr. P. J. Pharnacent. Bioned Anal 2005. 37.851.

4. Espinosa-Mansilla, A.: de la Pena, A. M.: Gomez. D. G.: CanadaCanada. F. J. Seporation Sci. 2006. 29. 1969.

5. Gonzalez. C.: Moreno, L.: Small. J.: Jones, D. G.; Bruni, S. F. S. Anal Chim. Acta 2006.560 .227

6. Nagaralli. B. S.: Seetharamappa. J.: Melwanki. M. B. J. Phamaceut. Bioned Anal. 2002. 29.859.

7. Pascual-Reguera, M. I.: Parras. G. P.; Diaz. A. M. Mficrochem. J. 2004. 77,79.

8. Michalska. K.: Pajchel G.: Tyski, S. J. Chromatogr . 2004 , 1051. 267.

9. Vilchez. T. L.: Araujo. L.: Prieto. A.: Navalon. A. Anal Chin Acta 2004. 516. 135.

10. Zhang. Z. Y.; Li. X.: Wang. X. L.: Chen, S. L.; Song. B. H.: Zhao. H. C. J. Raw Earths 2006. 24. 285.

11. Sun. H. W. Li. L. Q; Chen. X. Y. Anal Bional. Chem 2006 $38+.1314$.

12. Torriero. A. A. T.: Ruiz-Diaz. .. J. T.: Salinas. E.: Marchewsky. E J.: Sanz. M. I.: Raba. T. Talanta 2006. 69.691

13. Connors, T. F.: Rusling. J. F.: Owlia A. Anal Chem. 1985. 57. 170.

14. Rusling, J. F.; Alaa-Eldin, F. N. J. Am. Chem. Soc. 1993, 15, 11891.

15. Plałšiæ. M.: Knaric. D.: Osoviæ. B. Electroanahsis 1994. 6. 469.

16. Yang. T.: Hu. N. F.: Ruslitig. J. F. J. Electroanal Chem 1999. 463.53.

17. Zhang. S. H.: Wu, K. B. Bull Korean Chem. Soc, 2004, 25. 1321.

18. Bard. A. J.: Faulker. L. R. Electrochemical Methods: Fumdontentols and Applications, John Wiley \& Sons. Ine.: New York, Chichester, Weinhein. 2001 